\title{
"Los judíos murieron como ganado, por tanto el ganado muere como los judíos". ¿Hay un holocausto animal?
}

Jorge Sierra Merchán

Universidad Autónoma de Colombia

(c) 


\title{
"Los judíos murieron como ganado, por tanto el ganado muere como los judíos". ¿Hay un holocausto animal?'
}

\begin{abstract}
Resumen: un mínimo de coherencia y decencia moral haría que las personas que comen carne tuviesen que enfrentar la dura acusación que lanza Coetzee y PETA: tales personas son una especie de neonazis porque permiten, e incluso auspician, que millones de seres valiosos y sintientes mueran en esos actuales campos de concentración llamados mataderos y granjas industriales. Pero ihay un modo de hacer frente a tal acusación sin negar hechos evidentes sobre el sufrimiento y el valor de la vida de los animales no humanos? El objetivo del presente texto es explorar tres posibles respuestas a tal acusación. La primera sostiene que el animalista cae en el antropomorfismo al adjudicar erróneamente personalidad a los animales. La segunda sostiene que el desacuerdo moral entre animalistas y no animalistas es un enfrentamiento de intuiciones morales incompatibles que no puede ser resuelto de manera racional a través de la argumentación. La tercera afirma que la apelación a la empatía no produce preocupación moral por los animales. Un contraejemplo frecuentemente citado sobre la conexión entre crueldad y empatía es el amor generalizado para con los animales por parte del Tercer Reich.
\end{abstract}

Palabras clave: neonazismo, ética animal, persona, Holocausto, antropomorfismo.

\section{"The jews died like cattle, therefore cattle die like jews". Is there an animal holocaust?}

\begin{abstract}
A minimum of coherence and moral decency would make people who eat meat have to face the harsh accusation that Coetzee and PETA throw: such people are a kind of neo-Nazis because they allow, and even encourage, millions of valuable and sentient beings to die in those new concentration camps called slaughterhouses and industrial farms. But is there a way to deal with such an accusation without denying obvious facts about the suffering and value of animal life? The aim of the present text is to explore three possible answers to this accusation. The first argues that the animalist falls into anthropomorphism by wrongly assigning personality to non-human animals. The second holds that the moral disagreement between animalists and non-animalists is a confrontation of incompatible moral intuitions that cannot be resolved rationally through argumentation. The third affirms that the appeal to empathy does not cause moral concern for animals. A frequently cited counterexample of the connection between cruelty and empathy is the generalized love of animals on the part of the Third Reich.
\end{abstract}

Keywords: neo-nazism, animal ethics, person, holocaust, anthropomorphism.

Fecha de recepción: 28 de abril de 2017

Fecha de aceptación: 5 de junio de 2017

Forma de citar APA: Sierra Merchán, J. (2017). "Los judíos murieron como ganado, por tanto el ganado muere como los judíos". ¿Hay un Holocausto animal?

Revista Filosofía UIS, 16(2), doi: http://dx.doi.org/10.18273/revfil.v16n2-2017012

Forma de citar (Harvard): Sierra Merchán, J. (2017). "Los judíos murieron como ganado, por tanto el ganado muere como los judíos". ¿Hay un Holocausto animal? Revista Filosofía UIS, 16(2), 257-281.

Jorge Sierra Merchán: colombiano. Doctor en Filosofía de la Universidad Nacional de Colombia. Profesor Universidad Autónoma de Colombia.

Correo electrónico: jorgemill65@yahoo.com; jesierram@unal.edu.co

\footnotetext{
* Artículo de reflexión derivado de investigación.

1 Este artículo es el resultado parcial del proyecto de investigación (en curso) "¿Es la pertenencia a la especie humana un concepto moral?", adscrito al grupo (reconocido por Colciencias) Teoría y praxis contemporáneas de la política de la Facultad de Ciencias Humanas de la Universidad Autónoma de Colombia.
} 


\section{"Los judíos murieron como ganado, por tanto el ganado muere como los judíos". ¿Hay un holocausto animal?}

\section{Introducción}

PETA (personas a favor del tratamiento ético para los animales) usó, en 2003, una serie de ocho imágenes de gran formato en las que se evidenciaba el sufrimiento humano durante el Holocausto, al lado de imágenes que mostraban el sufrimiento de animales no humanos en la agricultura moderna ${ }^{2}$. Por ejemplo, había una foto de un hombre desnudo y demacrado junto a la de una vaca famélica. Con sus largas piernas flacas y las costillas salientes, las dos figuras exhibían perturbadores parecidos. La foto estaba acompañada del texto "El Holocausto en su plato. Durante los siete años transcurridos entre 1938 y 1945, 12 millones de personas perecieron en el Holocausto. El mismo número de animales es asesinado cada 4 horas para convertirse en comida en USA". Cuando los principales medios de comunicación se enteraron y, mucha gente a través suyo, de la campaña de PETA, se mostraron confundidos e indignados. Hubo denuncias apasionadas por prominentes judíos que hablaban de una profanación de la memoria de las víctimas del Holocausto y acusaban a los defensores de los animales de complicidad con los nazis y de repugnante amarillismo ${ }^{3}$. Pero, por otra parte, hubo varias voces de la comunidad judía que apoyaron el uso del Holocausto por parte de PETA, las cuales son recogidas y analizadas por Sztybel (Sztybel, 2006), quien escribe una importante defensa de dicho uso. Incluso, la comparación ya se había hecho antes por parte del famoso escritor judío Isaac

\footnotetext{
2 Por cuestiones de estilo, en adelante hablaré de animales, dando por sentado que se trata de animales no humanos.

${ }^{3}$ En cierto sentido, la analogía de PETA con el Holocausto, pudo ser más radical. Uno podría pensar que si la analogía quiere capturar el horror de los mataderos, debería ser más estrecha. Pero probablemente las personas no aceptarían que se utilicen fotos de alguna masacre de seres humanos y se las ponga al lado de vacas descuartizadas, como medio para generar preocupación moral por los animales. De hecho, hay otro problema con la analogía. Las mismas víctimas de una masacre resultarían ser victimarios (en caso de que consumieran carne) de otra masacre perpetrada en contra de los animales,
} 
Bashevis Singer, quien en su obra The Letter Writer (1964) escribió: "Todas las demás criaturas fueron creadas únicamente para proporcionarle alimento y vestido, para ser atormentadas y exterminadas a su antojo. En lo que a ellas se refiere, todos los humanos son nazis; para los animales, la vida es un Treblinka sin fin" (citado por Patterson, 2009, p. 7). Doce años después, otro judío sobreviviente del Holocausto, Alex Hershaft, fundó en 1976 Farm Animal Rights Movement, motivado por razones análogas a las de Bashevis Singer. Y más recientemente, el nobel de literatura J. M. Coetzee ha planteado la relación entre ambos genocidios en los siguientes términos:

\begin{abstract}
"Como ovejas al matadero". "Murieron como animales". "Los mataron los carniceros nazis". En las denuncias de los campos de concentración reverbera tan profusamente el lenguaje de los mataderos y los corrales que ya apenas es necesario que prepare yo el terreno para la comparación que estoy a punto de hacer. El crimen del Tercer Reich, dice la voz de la acusación, fue tratar a las personas como a los animales (Coetzee, 2004, p. 70).

Déjenme decirlo abiertamente: estamos rodeados de una industria de la degradación, la crueldad y la muerte que iguala cualquier cosa de la que fue capaz el Tercer Reich, incluso la hace palidecer, dado que la nuestra es una industria sin fin, que se auto-regenera, que trae al mundo conejos, ratas, aves de corral y ganado con el único propósito de matarlos (70-71).
\end{abstract}

Pero ies justificable moralmente la comparación, por parte de Bashevis Singer, Hershaft, PETA y Coetzee, del sufrimiento y la muerte animal con el Holocausto? ¿Son los seres humanos cómplices mudos de otro gran genocidio, un Holocausto animal, al permitir y promover que se mate y se maltrate a tantos animales, del mismo modo que los alemanes corrientes fueron cómplices del suyo? Si nuestra ignorancia de tal hecho es elegida, entonces nuestra culpa es inexcusable. Supongamos que está fuera de toda duda que los animales sienten placer y dolor. Por tanto, estaría mal producirles dolor sin ninguna justificación y matarlos sería injusto porque se los privaría de experiencias futuras de placer que podrían experimentar, como lo ha dejado en claro Peter Singer (1993) Por ello, claramente sería malo matar animales con el único fin de disfrutar del sabor de su carne. Un mínimo de coherencia y decencia moral haría que las personas que comen carne tuviesen que enfrentar la dura acusación que lanza Coetzee y PETA: todas las personas que comen carne son una especie de neonazis porque permiten, e incluso auspician, que millones de seres valiosos y sintientes sufran y mueran en esos nuevos campos de concentración llamados mataderos y granjas industriales. Pero ihay un modo de hacer frente a tal acusación sin negar hechos evidentes sobre el estatus moral de los animales que permiten luchar contra el sufrimiento y a favor de la vida de los animales? 
La lucha por los supuestos derechos de los animales requiere llevar las exigencias de justicia moral y política más allá de los límites de la especie humana. Por ello habría que rechazar por "especista", todo intento de dar prioridad moral a los seres humanos por el hecho de pertenecer a la especie humana, independiente de si son seres sintientes o personas. Conceder prioridad moral solo a los seres humanos simplemente por el hecho de que son humanos, implicaría un trato discriminatorio injustificado hacia las otras especies de animales (Singer, 1993). Tal trato discriminatorio hacia otras especies ha sido condenado por los animalistas a través del llamado argumento de los casos marginales, el cual es considerado como el argumento central y común a las tres teorías fundamentales que defienden la existencia y el reconocimiento de derechos para los animales: la teoría utilitarista de Singer desarrollada sobre el principio de igual consideración de intereses inter especies; la teoría de los derechos de Regan (1983), basada en el concepto de valor inherente de la vida animal, merecedora por ello de derechos; y la teoría de Nussbaum (Nussbaum, 2008), basada el enfoque de las capacidades que considera como un deber directo de justicia respetar dichas capacidades de los animales. El argumento de los casos marginales busca mostrar que los animales, como los "casos marginales" de la especie humana (los bebés y las personas con retraso mental), son pacientes morales que merecen protección gracias a que comparten el atributo de la sintiencia. Por lo tanto, la mejor defensa de los derechos de los animales se basa, no en que los animales son personas, sino en que son capaces de sufrir y en que tal sufrimiento es un mal innegable para quien lo padece.

El objetivo del presente texto es explorar tres posibles respuestas a tal acusación. La primera sostiene que una forma de enfrentar la acusación de neonazismo es atribuir al defensor de la vida animal una especie de distorsión de la realidad denominada antropomorfismo, una ilusión cognitiva (o sesgo) consistente en atribuir capacidades y estados mentales propios de los seres humanos a los animales sin ninguna justificación. Para tal fin, desarrollaré el argumento del sesgo cognitivo basado en desarrollos recientes en ciencia cognitiva evolutiva. Es claro que, a diferencia de los judíos, los animales no son personas, esto es, seres autoconscientes y racionales, sino solo seres sintientes (Singer, 1993). Por ello, la comparación con los judíos fallaría ${ }^{4}$. La segunda sostiene que el desacuerdo moral entre animalistas y no animalistas puede ser interpretado como un caso de enfrentamiento de intuiciones morales incompatibles que no puede ser resuelto de manera racional a través de la argumentación y de la apelación a hechos morales objetivos o realismo moral. Por lo tanto, no es posible tener una justificación adecuada a favor de la tesis de que los animales son personas, la

\footnotetext{
${ }^{4}$ Es notable que en un texto tan riguroso en examinar la comparación del Holocausto con la cuestión animal (Sztybel, 2006), el autor ni siquiera se tome la molestia de demostrar que los animales son personas. Simplemente se asume como un supuesto incuestionado. De ahí, la importancia de mirar el origen cognitivo y evolutivo de tal supuesto en nuestra tendencia innata a antropomorfizar.
} 
cual es crucial para la afirmación de que hay un Holocausto animal. La tercera afirma que la empatía no genera preocupación moral por los animales y los seres humanos. Según algunos animalistas, el desprecio por el dolor ajeno animal descansa en la misma insensibilidad (o falta de empatía) del torturador, del sicario, del secuestrador, del violador de seres humanos, según se puede leer en el Proyecto de Ley 172 de $2015^{5}$. Lo mismo podría decirse de la falta de sensibilidad de los nazis por el dolor de los judíos. Según los animalistas, fue gracias a que ya estaba desarrollada y aceptada socialmente la violencia contra los animales que el Holocausto fue posible ${ }^{6}$. La misma insensibilidad explicaría el genocidio animal. Sin embargo, tal planteamiento no parece ser correcto. Un contraejemplo frecuentemente citado sobre la conexión entre crueldad y empatía es el amor generalizado hacia los animales por parte del Tercer Reich, cuyos miembros fueron pioneros en el reconocimiento de derechos a los animales. Además, si la violencia generalizada contra los animales es condición para el genocidio ipor qué no se produjo en otros países el Holocausto sino sólo en Alemania?

\section{Antropomorfismo y el argumento del sesgo cognitivo}

A primera vista, parece que el uso que hace PETA del Holocausto es moralmente defendible debido a la magnitud del sufrimiento de los animales producida por su explotación institucionalizada. Sin embargo, mientras que los grupos bienestaristas apuntan sólo a persuadir al público para que sean más compasivos con los animales, los grupos abolicionistas, como el Frente de Liberación Animal, se orientan hacia la promulgación de principios abolicionistas a través de la acción directa, en lugar de persuadir al público de estos principios. Por ello, PETA se enfrenta al desafío distinto de confiar en su retórica exhortativa para incitar al público a reevaluar radicalmente su visión de los animales. En este contexto, se puede argumentar que la analogía con las experiencias de sufrimiento humano es una herramienta poderosa e indispensable. Pero algunos críticos han señalado que PETA debería haber seguido a los grupos bienestaristas, los cuales critican la agricultura en sus propios términos sin necesidad alguna de acudir a comparaciones con el sufrimiento humano. Pero esta crítica no alcanza un punto importante. Mientras que la Sociedad Protectora de Animales de los Estados Unidos trata de persuadir al público de que trate mejor a los animales de granja, el objetivo de PETA es nada menos que el de persuadir al público de que se debe detener por completo la agricultura y el consumo de animales. PETA debe persuadir a la gente no sólo de que la institución es cruel, sino que es moralmente atroz y para lograr esto, deben demostrar que los animales tienen un valor moral

\footnotetext{
${ }^{5}$ La discusión de este proyecto llevó a la Ley 1774, la cual fue sancionada por el Presidente de Colombia el 6 de enero de 2016 y en la que se reconoce que los animales no son simples semovientes, sino seres sintientes con una serie de derechos.

${ }^{6}$ Como afirma Coetzee: "Los judíos murieron como ganado, por tanto el ganado muere como los judíos"(2004, p. 729).
} 
intrínseco y que su sufrimiento es comparable al sufrimiento humano. Pero, pese a la similitud de las representaciones del dolor humano y animal, los espectadores sólo sintieron horror ante las imágenes de sufrimiento humano y, poco o ninguno, ante las imágenes de sufrimiento de los animales. La campaña sólo sirvió para que el endogrupo (los miembros de PETA) reforzara su compromiso a favor de los animales. ¿Cómo se puede explicar esta asimetría? ¿Son los animalistas víctimas de un sesgo cognitivo, el antropomorfismo, que opera a favor de su valoración de la vida de los animales?

Quienes defienden tal estrategia basada en la existencia de un sesgo, nos recuerdan que, por ejemplo, películas como Babe, Pollitos en fuga, Nemo, El planeta de los simios inducen, de manera acrítica, una especie de ilusión cognitiva (sobre todo en los niños) que permite una sobreatribución de capacidades y sentimientos a los animales, y por ello, genera una lucha por sus derechos que no se compadece con la realidad de su vida mental. La atribución de estatus moral y legal a los animales es un grave equívoco porque se basa, a su vez, en un enorme error cognitivo producto de un sesgo. Pero iqué tanto depende la defensa de la vida de los animales de una imagen supuestamente sesgada debida a una sobreatribución de rasgos de importancia moral a su vida mental? Sólo basta repasar de nuevo muchas de las imágenes que se muestran en tales películas: un cerdito parlante con una vida mental compleja y con planes de vida moralmente valiosos. Unos pollitos parlantes y pensantes que actúan con base en intenciones y que buscan escapar del "campo de concentración" en el cual se hallan injustamente confinados y condenados a muerte. La imagen hiperbólica de César, un simio parlante que se rebela en contra de la tiranía humana y busca redimir a sus hermanos simios. Imágenes inquietantes que sólo conmueven a los niños y a los veganos, sostiene el crítico del animalismo. Pero zqué papel cumplen el cine, la publicidad y la televisión en la fiabilidad de los procesos de formación de creencias acerca de la vida mental de los animales? Como lo plantea Ogien:
¿Algunas de las causas de intuiciones morales podrían bastar para descalificarlas? Si nos enteráramos, por ejemplo, de que nuestras intuiciones morales a favor de los derechos de los animales no tienen otra causa más que el sentimiento de amor inconfesado por el personaje de Bambi, ¿habría que tenerlas en cuenta en el debate moral? (2009, p. 100).

Parece, entonces, que muchas de nuestras creencias acerca de las mentes animales son formadas por procesos poco fiables. Tenemos, entonces, el siguiente argumento:

Argumento de la campaña publicitaria

1. Intuitivamente interpretamos psicológicamente a los animales.

2. Desde niños estamos rodeados por estrategias persuasivas implícitas, que presentan a los animales como seres psicológicamente ricos en el mismo sentido que lo son los humanos, incluso aunque ello suponga deformar su comportamiento real, como sucede en las tiras cómicas. 
3. Los entornos narrativos y televisivos informan nuestra comprensión cotidiana de la mente animal.

4. Nuestras intuiciones están informadas por el deformado comportamiento animal de las fábulas y la televisión, y por el uso del vocabulario psicológico que en ellas se encuentra.

5. Nuestras intuiciones interpretativas de tipo psicológico se basan en una campaña publicitaria implícita a favor de la interpretación psicológica de la mente animal.

6. Por lo tanto, nuestras intuiciones interpretativas no son psicológicamente fiables (Pérez, 2011, p. 278, énfasis propio).

Pero ide qué depende esta interpretación psicológica de la mente animal que lleva a considerar erróneamente que los animales son personas? Me parece que es posible dar un argumento más general que explique tal interpretación sesgada. Según la epistemología evolutiva, las fuerzas biológicas y, en particular la selección natural, son determinantes en la estructuración de la cognición humana y en la producción de sesgos cognitivos (De Cruz and De Smed, 2012). Tales consideraciones evolutivas sólo son relevantes para la justificación de las creencias desde una perspectiva externalista. Dentro de este contexto, en años recientes ha habido una explosión sin precedentes en la producción de argumentos evolutivos desacreditadores (AED), los cuales se definen como argumentos que apelan a la genealogía evolutiva de nuestras creencias (ya sean religiosas, morales o epistémicas) como un medio para cancelar su justificación y demostrar su irracionalidad (Kahane, 2011). Los llamados argumentos evolutivos desacreditadores (AED) se basan en un enfoque externalista de la justificación epistémica de la creencia centrada en la fiabilidad (o rastreo de la verdad) de los procesos formación de las creencias. Los AED tienen la siguiente estructura (Kahane, 2011):

Premisa causal: La creencia de $\mathrm{S}$ que $\mathrm{P}$ se explica por $\mathrm{X}$.

Premisa epistémica: $\mathrm{X}$ es un proceso que no rastrea la verdad.

Por lo tanto: la creencia de $\mathrm{S}$ que P es injustificada.

A su vez, la cuestión del rastreo de la verdad se define a partir la siguiente condición externalista de la justificación epistémica: un proceso rastrea la verdad si y sólo si P no fuera verdadera, S no creería que P. Un ejemplo puede ayudar a entender lo dicho: María cree que sus hijos son más bellos y más inteligentes que el promedio, y hay una buena explicación evolutiva para esta sesgada creencia adaptativa. Su creencia no está correctamente conectada causalmente con los hechos del mundo, a saber, las cualidades objetivas de sus hijos. Por ello, María habría tenido esta creencia, independientemente de tales cualidades. Por lo tanto, la creencia de María es injustificada. Podemos formular, entonces, el siguiente argumento.

El AED del sesgo cognitivo hacia el antropomorfismo 
1. La creencia que los animales son personas se explica por un conjunto de procesos no inferenciales o intuitivos de formación de creencias tales como DDHA (dispositivo detector de agentes hiperactivo) y ToM (teoría de la mente).

2. DDHA y ToM producen procesos no inferenciales de formación de creencias que no rastrean la verdad, dado que ambos, por razones evolutivas, producen más creencias falsas que verdaderas.

3. Por lo tanto, DDHA y ToM producirán la creencia que los animales son personas, sea o no el caso que los animales sean personas.

4. Si DDHA y ToM producen la creencia que los animales son personas, entonces DDHA y ToM proyectan un claro sesgo hacia el antropomorfismo en el proceso inferencial de formación de la creencia que los animales son personas, esto es, que el animalista creerá que los animales son personas, haya o no evidencia inferencial a favor de la verdad de dicha creencia.

5. Un proceso inferencial de formación de creencias no rastrea la verdad si produce la creencia que los animales son personas, exista o no evidencia inferencial a favor de su verdad.

6. Por lo tanto, la creencia que los animales son personas carece de justificación.

7. Por lo tanto, es irracional sostener dicha creencia.

A favor de la premisa crucial 2, es posible argumentar que DDHA es un mecanismo de detección de agentes que es adaptativo porque permite ser cauteloso en situaciones de riesgo potencial cuando haya sospechas de depredadores. Si el mecanismo no es muy sensible al entorno, será por ello menos adaptativo, pero si es hipersensible lo será más. Dada esta mayor sensibilidad o hiperactividad, el mecanismo tenderá a producir un número elevado de falsos positivos. El dispositivo detector de agentes es, entonces, hiperactivo (DDHA) por razones adaptativas (Dennett, 2007, p.140). Algunos procesos cognitivos pueden fallar por el lado de la precaución, si se tiene en cuenta que los costos o beneficios de los falsos positivos (detección de un depredador cuando no hay ninguno) y de los falsos negativos (no detectar un depredador que está presente) son asimétricos. Por ello, la selección natural tenderá a promover creencias que producen los más altos beneficios e incurren en los costos mínimos. Los seres humanos tienen un fuerte sesgo cognitivo a interpretar evidencia ambigua como si fuera causada por un agente. Esto explicaría porque algunos creen que los animales son personas. Entonces la explicación de DDHA es un desarrollo de la idea de Guthrie (1993) de que el antropomorfismo es una característica central de nuestro sistema cognitivo. Guthrie argumenta que el antropomorfismo es una estrategia funcional de las mentes humanas debido a que están diseñadas para producir mucha información relevante, cuanta sea posible, acerca del medio ambiente. Guthrie señala que personas y agentes son los objetos más complejos que nuestro sistema cognitivo conoce: tenemos un número enorme de sistemas cognitivos para procesar la interacción social. Nuestra tendencia a antropomorfizar se explica por medio de la selección natural: los agentes son más relevantes para la autopreservación y la adaptación que los objetos o artefactos. Otra razón para esta hipersensibilidad es que si un objeto es categorizado como un agente (una persona o un animal) entonces la psicología popular se activa y proporciona una 
multitud de hipótesis que pueden ser verificadas. Por lo tanto, con el fin de adquirir nueva información a acerca del medio ambiente, es bastante económico categorizar a tantos agentes como sea posible.

Cuando se vive en grandes grupos, es muy valioso tener la capacidad de poder predecir la conducta de los otros individuos. Se asume entonces la perspectiva intencional o ToM (teoría de la mente) para explicar que los comportamientos de los demás obedecen o están motivados, por creencias y deseos propios de los agentes humanos. La posesión de la perspectiva intencional, además de permitir la predicción del comportamiento ajeno, pone a disposición el desarrollo de estrategias para obtener recursos cuando se compite por ellos con los demás e incluso para hacer que los demás actúen en mi beneficio, ya sea a través del engaño o de la persuasión. Una vez que los seres humanos poseen esta tendencia a antropomorfizar (en el sentido de buscar agentes similares a ellos, por ejemplo, ver rostros humanos en las nubes y personas en los animales), serán por ello propensos a tomar los eventos que disparan o activan el DDHA como oportunidades para formar creencias acerca agentes que poseen mente. Este hecho terminaría por explicar el sesgo antropomórfico que yace en la mente humana (Dennett, 2007, p. 142). Por ejemplo, si, como ya mencionamos, la mente humana tiene una clara tendencia innata a buscar agencia en todos lados, entonces nuestra naturaleza, proclive y sesgada a creer en agentes con mente de manera injustificada, pondría en entredicho nuestra capacidad evaluativa y crítica frente a la tesis de que los animales son personas. Es más, se puede sostener que la incapacidad para convencer a un animalista de que sus argumentos no son válidos, se podría deber a tal sesgo. Los animalistas, inducidos por tal sesgo, no necesitan razones para creer, por lo cual las razones en contra de su creencia tienen poca eficacia argumentativa, como se evidencia, por ejemplo, en las enconadas discusiones entre defensores y opositores de la tauromaquia.

Tenemos entonces la siguiente proposición: si DDHA y ToM nos predisponen a aceptar la creencia que los animales son personas, entonces también nos predispondrá a aceptar los argumentos a favor de tal creencia. De este modo, el argumento del sesgo combina la falta de fiabilidad en dos niveles: en la producción no inferencial de la creencia animalista y en la producción inferencial de dicha creencia. La falta de fiabilidad del primer tipo produce la falta de fiabilidad del segundo tipo. Por lo tanto, el animalista creería que los animales son personas, tanto si hay buenas razones como si no las hay, porque creería que los animales son personas gracias a DDHA y ToM. Este argumento parece ser un caso del denominado sesgo de confirmación, esto es, de la tendencia a buscar y a centrarse en evidencia que parece confirmar lo que ya creemos y, por el contrario, pasar por alto la evidencia que parece ir en contra, lo cual implicaría que los argumentos o razones no cumplen ningún papel en la justificación de tales creencias.

El hecho de que algunos crean inferencialmente en la personalidad de los animales puede ser explicado suponiendo que hay dos tipos de procesamiento de información 
y dos conjuntos de creencias correspondientes: intuitivas y reflexivas. Mientras que la estrategia del animalista está basada sobre el razonamiento reflexivo, la estrategia básica no reflexiva está anclada en nuestros sistemas cognitivos automáticos. Por un lado, la estrategia reflexiva produce creencias complejas que son sostenidas explícitamente y verbalmente comunicadas. Tales representaciones son abstractas, difíciles y lentas de procesar. La distinción entre los dos tipos de creencias demuestra el papel decisivo del procesamiento cognitivo implícito (creencias intuitivas producidas por DDHA y ToM) en la explicación de por qué la gente tiende a formar cierto tipo de creencias reflexivas, aunque, como vimos sin ninguna validez. El intento de argumentar a favor de la personalidad de los animales descansa en una creencia intuitiva y automática que sólo convence a los que ya están previamente "convencidos" por tal sesgo.

Pero ¿quiere decir, según todo lo anterior, que no hay algo de verdad en la denuncia de los animalistas según la cual el sufrimiento animal importa? Probablemente, los animalistas tengan razón en que los animales sufren y ese sufrimiento importa desde un punto de vista moral. Incluso, para el caso de los judíos, la deshumanización y la degradación de la vida humana se convirtió en un asunto de animalizar al otro. Es bien sabido que los nazis deshumanizaban a sus víctimas para poder matarlas más fácilmente: las convertían animales inmundos, sin nombre y sin personalidad legal, moral o humana: meros seres anónimos carentes de importancia moral destinados a la muerte. Pero si alguien es un animal porque se lo convierte en un animal, se lo puede matar como a un animal. Pues, después de todo, está bien matar animales. Matar a alguien como a un animal era matarlo de forma indigna. Quienes defienden los derechos humanos se oponen a tal tratamiento indigno que se le da a los seres humanos. Pero ży los derechos de los animales no cuentan? Si todos los animales fueran personas (seres racionales y conscientes de sí mismos), la idea de una ética animal sería realizable. El problema es que la gran mayoría de animales, sino todos, no son personas, sino sólo seres con capacidad de sentir placer y dolor. El planteamiento implícito de autores utilitaristas como Singer, es que es peor el sufrimiento infringido a las personas que a los seres que no son personas, como los seres sintientes. Por ello, carece de fundamento equiparar el Holocausto con el sufrimiento en masa de los animales porque claramente los animales no son personas ni pueden sufrir como ellas ${ }^{7}$.

\footnotetext{
Hay que dejar en claro que la cuestión de que el dolor animal importa desde un punto de vista moral es mucho más fácil de justificar que el asunto de la muerte de animales. Si uno sigue a autores como Peter Singer, matar seres sintientes como los animales, nunca es equivalente a matar personas. Ello se debe a que las personas tienen un interés básico en tener una vida continuada, algo que los animales, en tanto seres sintientes no poseen. Así, la adjudicación de un derecho a la vida supone que sólo los seres autoconscientes, como las personas, pueden desear estar vivas porque para tener derecho a la vida se debe poder desear aquello a lo que se tiene derecho, esto es, se debe poder desear estar vivo. Algunos animales que tienen un interés moralmente importante en evitar el sufrimiento pueden no tener un interés moralmente importante en continuar viviendo. Por lo tanto, la exigencia moral consistiría en no comer carne que sea producto de un trato cruel a los animales. Para Singer, no es intrínsecamente malo comer carne, y tampoco matar animales cuyas vidas no estén sometidas a maltrato y cuya muerte sea indolora. Obviamente, muchos animalistas
} 


\section{Desacuerdo moral y escepticismo}

Pero si, de nuevo, se insiste en que casi todos somos una especie de neonazis, entonces isomos presa de una ilusión cognitiva masiva en sentido contrario al del antropomorfista, la antroponegación, es decir, no vemos que estamos matando a nuestros semejantes no humanos? La antroponegación denota una ceguera voluntaria hacia las características humanas de los animales tanto como hacia las características animales de los humanos. Y si ese es el caso, ¿cómo es posible salir de esta situación de error cognitivo, esa especie de caverna moral en la que nos encontramos confinados? ¿Tiene sentido la argumentación entre visiones de mundo que parecen irreconciliables e inconmensurables, pues, claramente el animalista como el consumidor de animales no ven lo mismo? ¿Eso es carne o el pedazo de un cadáver de un víctima? ¿Son sólo huesos o los preciados restos de un amado animal? ¿Tienen los animales una dignidad comparable a la humana que no vemos y que los animalistas sí? Si no vemos lo mismo, ¿es exigible amar a los animales? ¿Puede obligarse a alguien a sentir y a ver de determinada manera la vida animal? Aquí puede ser de ayuda Hemingway.

Al tratar de intentar comprender qué es lo que uno ve y siente cuando se ve que se mata a un animal en las corridas de toros, Hemingway plantea la siguiente dificultad en su novela Muerte en la tarde:

Yo intentaba por entonces escribir y me parecía que la mayor dificultad para ello, aparte de saber lo que uno siente y no lo que debiera sentir o lo que a uno le han enseñado a sentir, estriba en trasladar al papel de manera sencilla un hecho, poniendo de relieve los sucesos que de verdad han creado la emoción experimentada (Hemingway, 1985, pp. 7-8. Énfasis propio).

La dificultad es doble. Por una parte, hay cierta indeterminación con respecto a lo que uno siente (placer por la muerte del toro), pero que no debería sentir (dado que le han enseñado a sentir que el dolor animal es malo). La otra dificultad es más profunda: si se trata de una experiencia de placer ante la muerte del toro, hay que dejar en claro en virtud de qué hechos se produjo tal emoción de placer. Obviamente, una persona sensible al dolor animal, no experimentará placer e interpretará ciertos hechos como causas de su malestar (la sangre del toro, sus heridas, su fatiga, su incesante lucha, en suma, su sufrimiento). Pero claramente Hemingway no ve lo mismo, ya que puede interpretar los mismos hechos como significando lo contrario pues "...los toros son absolutamente morales para mí, porque, durante la corrida, me siento muy bien, tengo el sentimiento de la vida y de la muerte, de lo mortal y lo inmortal, y una vez terminado el espectáculo, me siento muy triste, pero muy a gusto" (10).

no están de acuerdo con Singer. 
Un escéptico moral dudaría acerca de la existencia de unos hechos morales objetivos sobre los que quepa fundamentar, de manera correcta, la emoción experimentada ${ }^{8}$.Un realista moral diría lo contrario: tales hechos existen. Si no fuera así, no habría defensores racionales de los animales. Los defensores de los animales describirían la situación a su favor porque verían el horror de las corridas. Pero si tales hechos no existen, los animalistas serían como una especie de fanáticos dogmáticos que sólo ven lo que quieren ver, pero que son incapaces de ver arte en el toreo. Si, como Hemingway reconoce, se defiende una forma de emotivismo moral, según la cual "es moral todo lo que me sienta bien y es inmoral todo lo que me sienta mal", entonces las corridas son morales porque hacen que el escritor se sientan bien. En el caso del defensor de los animales, las corridas son inmorales porque hacen que él se sienta mal. Dado que ambos no ven lo mismo y no sienten lo mismo, no pueden concordar en la corrección o incorrección moral de las corridas.

Una manera de describir el descuerdo moral entre Hemingway y el animalista, desde el punto de vista emotivista, sería que uno no reconoce las razones morales del otro porque ambos no sienten lo mismo. Llamar irracional al amante de las corridas sería un despropósito, del mismo modo que llamar irracional al animalista por no saber apreciar al arte del toreo. Dado que el realismo moral es insostenible y no hay hechos morales que le den la razón a nadie, entonces parece ser que el desacuerdo moral entre defensores y opositores de las corridas de toros es insuperable a través de la discusión racional y de nuestra capacidad para evaluar creencias morales incompatibles basadas en intuiciones.

Supongamos que un liberal quiere convencer, digamos a Hemingway, de que acepte tratar a los animales como iguales y condene las corridas de toros. La reacción del escritor, como es obvio, será de indignación al sentirse moralmente insultado ante la sugerencia de que debe tratar a un animal como si fuera una persona. "No se puede tratar a un toro como si fuera una persona", sería su réplica. ¿Serviría de algo recordarle a nuestro honorable escritor que el sujeto que tiene en frente es un paciente moral con derecho a la vida? "Toda persona racional sabe que a los toros se los puede matar impunemente", es lo que Hemingway le diría al animalista. Desde un punto de vista emotivista, el escritor no está siendo irracional al afirmar lo que afirma porque es lo que de verdad siente. La identidad moral del escritor es inseparable de su sentido de lo que es (un amante de los toros) y de lo que él no es (un animalista). Claramente él no es uno de esos raros animalistas que son solidarios con el dolor animal. Igualmente, el animalista tampoco sería irracional desde su propio punto de vista.

\footnotetext{
${ }^{8}$ La duda de este escéptico afecta al realismo moral, el cual se define por tres rasgos: 1) los juicios morales expresan creencias, 2) algunas creencias morales son verdaderas y 3) la verdad de estas creencias es independiente, es decir, su verdad no depende de las actitudes que cualquier agente moral tenga hacia su contenido. Así definido, el realismo moral es contrario al emotivismo moral, el cual sostiene que tales actitudes valorativas es todo lo que hay en una creencia moral.
} 
Esto nos lleva a plantear el siguiente argumento:

El Argumento del desacuerdo moral a favor del escepticismo

1) Si hay un desacuerdo moral fundamental y generalizado, muchas personas tendrían un número significativo de creencias morales falsas, aunque emplearan perfectamente nuestro mejor método de investigación moral ${ }^{9}$.

2) Si muchas personas tuvieran un número significativo de creencias morales falsas (incluso si aplicaran perfectamente nuestro mejor método de investigación moral), entonces tal método no sería fiable para muchas personas.

3) Si uno es consciente de que nuestro mejor método de investigación moral no es fiable para muchas personas, entonces uno no puede estar justificado en creer los resultados de tal método, a menos que tenga una razón especial para creer que es fiable en su propio caso.

4) No es el caso que cualquiera de nosotros tenga una razón especial para creer que el mejor método de investigación moral es fiable en nuestro propio caso.

5) Por lo tanto, si nos damos cuenta de un amplio desacuerdo moral fundamental, entonces no podemos estar justificados en creer en los resultados de nuestro mejor método de investigación moral (Horn, 2016, p. 12).

El hecho innegable sobre la existencia de creencias morales incompatibles implica un reto adicional muy fuerte para la justificación de la creencia del animalista. En años recientes ha habido una gran cantidad de discusión sobre la importancia epistémica del desacuerdo y sus implicaciones en la justificación de las creencias morales (Machuca, 2013). En general, se supone que al saber que existen pares epistémicos, esto es, que hay gente sincera, moral y epistemológicamente virtuosa, inteligente y reflexiva que sostiene una determinada creencia moral incompatible con la propia, amenaza con cancelar cualquier justificación de la creencia moral. Esta amenaza surge de la idea de que ambas creencias se deben tratar racionalmente como casos iguales. Es decir, la existencia de una aparente simetría epistémica entre las creencias morales de personas pertenecientes a diferentes tradiciones morales, desemboca en una situación en la que sería epistémicamente arbitrario afirmar la verdad de cualquier creencia moral de una forma exclusiva sobre las demás. Parece, entonces, que el siguiente principio cancelador de la justificación

\footnotetext{
${ }^{9}$ Horn explica en el siguiente texto la idea de mejor método de investigación moral : “(...) parece que hay un notable grado de consenso sobre cómo debe proceder la investigación moral en la práctica. A pesar de los desacuerdos epistemológicos más profundos, la mayoría de los filósofos ahora están de acuerdo en que nuestro mejor método de investigación moral consiste en intentar someter nuestras intuiciones bajo la idea de un equilibrio reflexivo a la luz de todos los hechos no morales pertinentes. Hacerlo implica revisar nuestros juicios morales particulares a la luz de los principios que aceptamos, y revisar esos principios a la luz de otros juicios morales y otros principios, con el objetivo de lograr un conjunto de opiniones morales que sean internamente coherentes y encajen cómodamente dentro del marco de nuestras creencias no morales sobre el mundo" (Horn, 2016, p. 12).
} 
de la creencia moral basado en la existencia de desacuerdo moral es verdadero: Si (1) S tiene alguna buena razón para creer que P, pero (2) también sabe que otras personas tienen igualmente buenas razones para creer cosas incompatibles con $\mathrm{P}, \mathrm{y}$ (3) S no tiene ninguna razón para desechar aquellas razones y favorecer las suyas, entonces S no está justificado en creer que P.

La consecuencia natural del desacuerdo moral parecería ser el escepticismo, ya que es ese estado hacia el que animalista se debería mover al ser consciente de la existencia de pares epistémicos, dado que no hay justificación para creer que los animales son personas. En este sentido, la existencia de desacuerdos, también plantea un reto para el crítico del animalismo, quien debe disminuir la confianza en su creencia o, incluso, verse abocado a cancelar la justificación a favor de ella. Pero el escepticismo generado por el desacuerdo moral inclina la balanza a favor del crítico del animalismo y cancela la justificación de la creencia animalista, bajo el supuesto que el animalista es un realista moral ${ }^{10}$. En efecto, si el desacuerdo entre pares conduce a aceptar el escepticismo, entonces el desacuerdo entre quienes sostienen una creencia animalista y quienes sostienen una posición contraria, dejará a los defensores de esta última postura en una mejor posición epistémica. Se supone que ante la imposibilidad de decidir racionalmente entre dos posiciones morales excluyentes, la opción más racional es suspender el juicio para los casos de desacuerdo en donde los pares epistémicos tienen la misma evidencia y llegan a diferentes conclusiones ${ }^{11}$. Pero como la explicación del desacuerdo tiene raíces externalistas, que muestran que la fuente de este reside en un proceso formador de creencias no fiable, como se demostró a través del argumento del sesgo hacia el antropomorfismo, entonces las razones del crítico del animalismo tendrán más peso al enfrentar a sus pares animalistas, si estos se escudan en el realismo moral ${ }^{12}$.

\footnotetext{
${ }^{10}$ Nussbaum y Regan adoptan una especie de realismo moral intuicionista de acuerdo con el cual los agentes morales captan intuitivamente el valor intrínseco de la vida animal presente en el mundo natural de manera objetiva, por lo que ambos no reconocen la validez de los enfoques constructivistas en ética.

${ }^{11}$ El intuicionismo parece conducirnos al escepticismo moral, debido a que cualquier creencia moral que sostuviéramos podría resultar errónea, pese a su carácter intuitivo y evidente. Es por ello que cuando se da un desacuerdo entre los principios morales básicos, el intuicionismo parece conducirnos inexorablemente a una especie de parálisis argumentativa, pues si las verdades morales autoevidentes no coinciden y hay desacuerdo, no es posible dar argumentos a favor de unas o de otras.

${ }^{12}$ De hecho, hay un argumento más general en contra del realismo moral. Según Street (2006):
}

1. Nuestros disposiciones normativas, es decir, nuestras disposiciones para formar ciertas creencias normativas en lugar de otras, son producto de nuestra historia evolutiva.

2. Nuestros disposiciones normativas fueron seleccionadas porque contribuyeron al éxito reproductivo al promover ciertos tipos de cooperación entre nuestros antepasados.

El argumento de Street tiene como objetivo socavar el realismo normativo, el cual sostiene que las verdades morales son independientes de nuestras creencias y actitudes morales. La idea es que las fuerzas evolutivas moldearon nuestras creencias morales al dar forma a las 
Hay otras formas de justificación de la moral (por ejemplo, el constructivismo moral) que no resultan afectadas por el argumento escéptico y que permiten que la discusión entre animalistas y críticos del animalismo continúe.

\section{Empatía y promoción de los derechos de los animales}

Una fuente de frustración para los especialistas en ética animal (Gruen, 2009; Aaltola, 2013; Nussbaum, 2008), al igual que para muchos defensores y activistas a favor de los animales, es la tenaz persistencia de un déficit de compasión frente a los evidentes daños morales infringidos a los animales. El remedio que a menudo se recomienda para esta apatía es la promoción de la empatía hacia ellos. Por ejemplo, podríamos pensar que tal insensibilidad se debe a una falta de comprensión de lo que se siente ser un animal sometido a maltrato. Ya se trate de cerdos hacinados y maltratados de camino al matadero o de chimpancés obligados a actuar en un circo, todos estos casos podrían ser evitados si la gente simplemente entendiera lo que se siente al estar en tales circunstancias ominosas. Se supone, entonces, que la empatía puede proporcionar este tipo de visión y de compresión del dolor animal ajeno. Pero ¿debe tener la empatía tal papel privilegiado en nuestra reflexión ética acerca de los animales?

Parece que si se rechaza la idea que la empatía es fundamental en generar preocupación moral, no sería posible promover un trato justo para los animales. En este sentido, se afirma que la empatía motiva la formación de actitudes y comportamientos positivos de protección a los animales mejor que cualquier otra emoción. Sin embargo, recientemente algunos autores han sostenido que la empatía no es el principal proceso psicológico responsable de producir preocupación moral por los animales (Aaltola, 2012; Kasperbauer, 2014). Son otras emociones morales, particularmente la ira o la indignación moral, las que

proto-versiones de dichas creencias. Sin embargo, las fuerzas evolutivas seleccionan para la supervivencia, no para la verdad moral. Por lo tanto, si realismo normativo es verdadero y la historia evolutiva acerca de la cognición moral es correcta, entonces la evolución ha empujado las creencias morales en una dirección que no tiene nada que ver con el rastreo de las verdades morales objetivas. El dilema darwinista contra el realismo normativo se resume en que, o bien el realista debe aceptar que las fuerzas evolutivas rastrean la verdad de los hechos normativos, o bien debe aceptar que no lo hacen. En el primer cuerno del dilema, el realista afirma que la fuerzas evolutivas rastrean la verdad. Pero el problema con elegir este cuerno es que no es plausible sobre bases empíricas. En tanto empírica, la hipótesis del rastreo de la verdad compite con otras hipótesis empíricas que buscan explicar la relación de la evolución con nuestras creencias normativas. De acuerdo con la hipótesis rival, la denominada explicación de la conexión adaptativa, nuestros juicios normativos han sido seleccionados solamente por sus efectos motivacionales, pero no porque sean verdaderos. Además, tal explicación naturalista es más simple, clara e ilustrativa que la hipótesis del rastreo de la verdad del realista, y por ello, es superior según los criterios para la evaluación de hipótesis empíricas. El otro cuerno del dilema conlleva a reconocer que las fuerzas evolutivas no rastrean la verdad de los hechos normativos. En ese caso, sería una gigante y asombrosa coincidencia si nuestros juicios normativos resultaran ser verdaderos. 
están más firmemente comprometidas con la producción de preocupación moral por los animales, por lo que serían más útiles que la empatía a la hora de alcanzar los deseados objetivos normativos que plantea la ética animal (Nussbaum, 2008).

El elemento más importante de la empatía es el intercambio de emociones. Aunque la cognición moral de alto nivel puede influir en este proceso, la mayoría de especialistas está de acuerdo en que la empatía es, en gran medida, automática e inconsciente. Por ejemplo, la empatía se describe a menudo en términos de "contagio emocional", esto es, como el intercambio de emociones inconscientes que resultan de la observación de las expresiones emocionales de los otros. Ejemplos típicos de contagio emocional son los casos en los que vemos a alguien sonreír o llorar e inevitablemente nos sentimos felices o tristes.

Un desafío tradicional al momento de dar cuenta de la empatía hacia los animales es determinar si estamos compartiendo realmente sus emociones o en su lugar sólo se trata de la proyección de nuestras emociones en ellos. Esto claramente afectaría la equiparación del sufrimiento animal con el sufrimiento judío. Si se caracteriza a la empatía como una manera de entender y compartir los sentimientos, emociones y comportamientos de otros, la empatía estaría relacionada con el fenómeno cognitivo de entender o "leer" las creencias, deseos e intenciones, que se conoce y ya caracterizamos como "teoría de la mente" (ToM), por lo cual habría cierto sesgo antropomórfico asociado a este hecho. Ya que a veces es difícil proporcionar condiciones de éxito para este proceso, sentir empatía por los animales parece ser algo deficiente y no seguramente algo capaz de proporcionar creencias morales definidas (Scotto, 2015). Pero hay diversas estrategias que permiten detectar más o menos cuándo hay una proyección indebida de nuestras emociones a los animales (Andrews, 2011; De Waal, 2009). Es decir, podemos, por ejemplo, entender que un animal sufre y diferenciamos este sufrimiento del sufrimiento al que está sometido una persona y nunca los equiparamos. Pero para lograr esto hay que luchar en contra de un sesgo poderoso. Probablemente algunos logren ver la diferencia, mientras otros no.

¿Es cierto que la disminución de la violencia contra los animales redunda en una reducción de la violencia contra los seres humanos y viceversa, como sostienen muchos animalistas en nuestro país y en el mundo? Según varios defensores de los animales, existe sin duda alguna, una inextricable relación entre aquellos que ejercen crueldad contra animales y aquellos que ejercen violencia contra humanos. La apatía por el dolor ajeno animal descansa en la misma insensibilidad del torturador, del sicario, del secuestrador, del violador de seres humanos. Algo análogo podría afirmarse sobre la falta de sensibilidad de los nazis por el dolor de los judíos. Fue debido a que ya estaba socialmente aceptada una forma de violencia contra los animales que el Holocausto fue posible. La misma insensibilidad o falta de empatía explicaría el genocidio animal. Pero ila empatía por los animales aumenta la empatía por los seres humanos? 
Algunos teóricos, como Kant y Aquino, afirman que la crueldad con los animales indica una propensión correspondiente con respecto a la crueldad con los seres humanos. Un evidente corolario de esto es que el tratar amablemente a los animales conduce a un trato bondadoso hacia los seres humanos. Pero se puede plantear la hipótesis de que la relación va en la dirección opuesta: la crueldad y amabilidad con los seres humanos indica una propensión similar con los animales. Este complejo de relaciones es importante para la empatía, ya que indica que la capacidad para la empatía, esto es, la capacidad para compartir emociones con entidades distintas de uno mismo, es generalizable. La bondad (o crueldad) con una clase de seres (humanos o no humanos) aumentará la bondad (o crueldad) con relación a la otra (Kasperbauer, 2014).

Es posible identificar dos implicaciones verosímiles a las que daría lugar la hipótesis de la generalización. Por un lado, la existencia de bienestaristas parece refutar la hipótesis de la generalización: su empatía está en sintonía más con los animales que con los seres humanos. Una diferencia fundamental con este grupo de personas, podríamos suponer, son sus experiencias con animales. Por otra parte, y en general, el asunto es discutido en términos de cómo las experiencias tempranas de maltrato animal durante la infancia les permite aprender a los niños sobre la cuestión del abuso en términos generales. La hipótesis de la generalización se puede tomar para hacer una afirmación similar, de manera que la empatía por los animales le enseñaría a la gente acerca de la empatía en general. No obstante, esto hace que sea difícil concluir que tal empatía es responsable del aumento observado en la empatía por los seres humanos.

Pero esto plantea una dificultad a la hipótesis de la generalización: ¿qué tipo de experiencia con animales es necesaria para el cultivo de la empatía? Una propuesta plausible es que es necesario tener experiencia en el cuidado de animales que permita garantizar la satisfacción de sus necesidades básicas. Esto haría probable también que la gente proporcionaría un cuidado a otros seres humanos y el mecanismo responsable sería la empatía. Pero esto implicaría que los protectores de animales, en general, tendrían una puntuación alta en empatía, mientras que la de los agricultores sería baja. Sin embargo, los agricultores indudablemente pasan mucho tiempo cuidando a los animales, por lo que deberían poseer más empatía. Por supuesto, alguien podría argumentar que esto es sorprendente porque los agricultores explotan a los animales y los usan para sus fines. Tal vez, alguien podría afirmar, que el cultivo de la empatía requiere un tipo correcto de cuidado, algo que los agricultores no proporcionan. Pero parece poco probable que los agricultores no tengan las experiencias correctas. A menudo, los agricultores son altamente sensibles al bienestar de sus animales, ya que, como mínimo, deben sentirlo con el fin de conseguir un beneficio. De este modo, deben mostrar una gran empatía si el cuidado de animales implica una fuerte relación con la empatía. En un estudio reciente sobre empatía, los resultados mostraron que tener una mascota está correlacionado con la empatía animal, pero no con la empatía humana (Aaltola, 2013). 
De este modo, el vínculo observado entre la empatía con los animales y la empatía con los seres humanos, no ocurrió gracias a la interacción con los animales (o al menos no con los animales domésticos). Este resultado apunta a un fenómeno común que se evidencia con la empatía: tendemos a ser parciales y tener empatía con aquellos que tienen relaciones especiales con nosotros. Los dueños de mascotas, por ejemplo, muestran, a veces, más empatía por sus mascotas que por los seres humanos. El caso es que, por el contrario, en lugar de generalizar nuestra empatía por los animales a los seres humanos, nos solidarizamos con los seres que están cerca, y esto, a menudo, involucra tanto a animales como a seres humanos. Para ilustrar mejor esto, hay que tener en cuenta los resultados del siguiente experimento (Kasperbauer, 2014, p. 820). Se le contó a varias personas un relato en el que se describe una situación en la que un hombre, una mujer, un gato y un perro se hallaban tirados en una calle con las costillas rotas y un pulmón perforado. Se pidió entonces a los participantes que evaluaran 16 emociones que podrían sentir, entre ellas la empatía. Bajo otras condiciones, una situación análoga se relató, pero, en este caso, con un niño humano y un cachorro. Asombrosamente, se encontró que los padres mostraron más empatía por los niños, mientras que los dueños de mascotas exhibieron más empatía por el perrito. Esta diferencia no se presentó para el caso de animales adultos. Se encontró que la empatía con los animales (ya sean perros o gatos) se correlacionó positivamente con la empatía con los seres humanos (ya sean hombres o mujeres), pero la experiencia con los cachorros y bebés crea empatía localizada adicional, en particular, sólo para esos grupos (Scotto, 2015). En conclusión, estos resultados permiten hablar en contra de la tesis de la generalización en la medida en que no hay una conexión causal discernible entre la empatía por los animales y la empatía por los seres humanos. Ni la empatía por los cachorros ni la empatía por los niños mostraron efectos generalizados. Por lo tanto, los animalistas, que sostienen lo contrario, están equivocados.

Pero ¿se debe a una falta de empatía la crueldad con los animales? La idea de que la empatía es necesaria para la preocupación moral supone la afirmación más elevada, según la cual sin la empatía no podemos expresar preocupación moral. Es más, algunos animalistas van más allá y dicen que la falta de empatía hace que la crueldad hacia los animales sea posible. La crueldad se materializa en abuso. De ahí la necesidad de promover la empatía. Sin embargo, la evidencia que relaciona el abuso de animales con las personas que carecen de empatía es mixta. Por ejemplo, se le preguntó a varios sujetos acerca de sus experiencias pasadas con animales, incluyendo los cuidados así como los abusos, para calcular su empatía. Los resultados indicaron que había una fuerte empatía reflejada en el cuidado de los animales. Es importante destacar que los que confesaron intervenir en el maltrato de animales no eran diferentes a los demás en la medida de empatía. Por lo tanto, lo que causa que la gente participara en el abuso animal no fue debido a un fracaso de la empatía. De hecho, el único elemento que permitió inferir maltrato animal fue el de haber sido abusado sexualmente durante la niñez (Henry, 2006). 
Un contraejemplo frecuentemente citado sobre la conexión entre crueldad y empatía es el amor generalizado de animales por parte del Tercer Reich (Arluke and Sax, 1992). Los nazis propusieron un ambicioso plan de leyes proteccionistas a favor de los animales que abogaban por la lucha contra la vivisección, la caza, el sufrimiento en la crianza de ganado y la extinción de animales salvajes, así como la promoción del vegetarianismo como un ideal moral. Además, estas leyes ambiciosas apelaban al valor no instrumental de los animales, los cuales no existían sólo para ser utilizados por los alemanes o por cualquier otra persona ${ }^{13}$.

(...) el pueblo alemán posee desde siempre un gran amor por los animales y siempre ha sido consciente de las elevadas obligaciones éticas que tenemos para con ellos. Aun así, sólo gracias a la Dirección Nacionalsocialista el deseo, compartido por círculos muy amplios, de una mejora de las disposiciones jurídicas respecto a la protección de los animales, el deseo de la promulgación de una ley específica que reconozca el derecho que poseen los animales en cuanto tales a ser protegidos por sí mismos ha sido llevado a la práctica (Fragmento de las leyes proteccionistas citado por Ferry, 1993, pp. 155-156).

También con frecuencia se citan diversas emociones relacionadas con la empatía en la justificación de sus acciones. Por ejemplo, uno de sus objetivos declarados en la promoción de las leyes de protección de los animales era despertar y fortalecer la compasión como uno de los más altos valores morales del pueblo ario. Sin embargo, los nazis son típicamente considerados como el arquetipo de la crueldad y la falta de sensibilidad, por lo que parece que sus rasgos crueles, o bien debe ser causados por algo no relacionado con la empatía (por ejemplo, la obediencia ciega a la autoridad), o bien por una forma muy específica de fracaso de la empatía.

Esta interpretación parece desesperanzadora, sólo si se supone que la empatía es el núcleo fundamental que hace posible la preocupación moral por lo demás. La empatía por los animales debe ser capaz de operar fuera de las situaciones en las que es relativamente fácil de producirse. Muchas industrias en las que se sabe que los animales son tratados cruelmente, incluyendo los laboratorios y las granjas, poseen precisamente el tipo de estructura autoritaria utilizado en los experimentos de Milgram sobre la obediencia ciega a la autoridad y su nexo con el maltrato a los demás. Si el hecho de no tratar bien a los animales en

\footnotetext{
${ }^{13}$ Aquí hay que tener en cuenta la salvedad (la cual comparto) que hace Ferry con respecto a la ecología y que yo hago extensiva a la evaluación crítica de la ética animal: "La presencia de un auténtico interés por la ecología en el seno del movimiento nacionalsocialista no constituye, en mi opinión, una objeción pertinente a la hora de hacer un examen crítico de la ecología contemporánea. Así las cosas, habría que denunciar como fascista la construcción de autopistas -es sabido que constituyó una de las prioridades del régimen nazi-. En este caso, como en ninguno, la práctica genealógica de la sospecha no es de recibo" (Ferry, 1993, p. 154).
} 
la agricultura intensiva, por ejemplo, es el resultado de un fallo de la empatía, entonces parecería que la empatía es demasiado débil para que de ella dependan muchas de nuestras obligaciones morales.

Cabe una última cuestión: inos motiva la empatía a actuar para alcanzar nuestros deberes morales? Una creencia generalizada es que la empatía es útil para ello. En general, las personas suelen valorar a los animales de manera positiva, reconociendo que se les debe un mejor trato. Sin embargo, fracasan estruendosamente a la hora de hacer lo correcto debido a una falta de motivación, como sucede en el caso de la agricultura industrial. Casi nadie niega que la agricultura industrial es moralmente problemática. Sin embargo, pocos toman medidas para mejorar el trato a los animales o para suprimir semejantes prácticas. La solución no está en la empatía, pues la empatía es un motivador débil (Prinz, 2011), y cuando logra motivar, los resultados a menudo son contrarios a fines morales defendidos por los animalistas, por ejemplo, al evitar que la gente coma carne. Incluso, comportamientos sádicos, que disfrutan con el dolor ajeno, suponen una forma de empatía. Parece ser que la empatía es un fuerte motivador de preocupación moral, siempre y cuando se dirija los miembros del endogrupo, como sucedió con la campaña de PETA. Al parecer la indignación moral y no la empatía, es la respuesta más clara a la cuestión de la motivación. Al combatir injusticias, por ejemplo a la hora de luchar en contra del maltrato animal, la investigación en psicología sugiere que la indignación es el mejor candidato para proporcionar motivación moral que la empatía (Nussbaum, 2008).

Si otras emociones son más importantes para la motivación moral, entonces ellas deben ser el centro de atención de los animalistas que buscan motivar la conducta moral de los demás. Hay que concluir que la empatía no fue decisiva en producir preocupación moral en la campaña de PETA por los animales. En lugar de ello, los especialistas en ética deben recurrir a la plétora de otras emociones morales hacia los animales. Ver cómo viven los animales evoca respuestas emocionales y nos impulsa a considerar si los estamos tratando bien o no. Esto incluye la indignación no sólo moral, sino todas las otras emociones que normalmente se sienten en respuesta a transgresiones morales: culpa, vergüenza, asco y desprecio, entre otras. Pero son estas emociones y no la empatía, las que tienen el potencial de producir una verdadera preocupación moral por los animales (Prinz, 2011; Nussbaum, 2008).

¿Cuál es entonces el papel de la indignación en la respuesta moral al maltrato contra diferentes tipos de animales? La investigación sobre la indignación como respuesta al trato cruel contra los seres humanos aún no se ha probado empíricamente con respecto a los animales (Oxley, 2011). Por ejemplo, sería interesante saber si la indignación moral muestra un sesgo similar en el endogrupo como en la caso de la empatía. Puede ser que las personas sean ciegas a las injusticias contra los animales que no son sus mascotas o no se perciben como miembros de grupos endógenos 
humanos. Una manera de probar esto sería ofrecer a las persona casos ficticios que impliquen daño a sus propias mascotas. La empatía, la indignación y otras emociones podrían entonces ser medidas y comparadas con diferentes expresiones de preocupación moral (por ejemplo, conductas de protección o castigo hacia el transgresor) para ver sus efectos en el endogrupo.

\section{Conclusión}

Si lo argumentado hasta aquí es correcto, entonces no es posible estar a favor de la existencia de un Holocausto animal. Es claro que los animales no son personas. Si bien los judíos murieron como ganado, el ganado no muere como murieron los judíos. Equiparar el sufrimiento y la muerte animal con el dolor y muerte de los judíos es un exabrupto que hizo contraproducente el uso del Holocausto por parte de PETA para la promoción de los derechos de los animales. Es claro que el crimen del Tercer Reich, fue tratar a las personas como si fuesen animales. Pero no hay crimen en tratar a los animales como no personas, esto es, como seres sintientes. Como mostré, esta característica es la base de su estatus moral y de la defensa de sus derechos. Lo que es claro es que los nuevos conocimientos que tenemos de la vida mental y afectiva de los animales se pueden utilizar para crear una ética humanitaria que tome en consideración, no sólo nuestros intereses en detrimento de los suyos. Somos iguales y somos distintos a los animales. Somos seres morales complejos y ellos seres morales menos complejos. Pero esta diferencia no se debe tomar como una deficiencia en contra de los animales, sino como una ventaja que puede ser utilizada a su favor. Podemos defender algunas reivindicaciones morales para los animales a través de la idea de que el sufrimiento animal es equiparable al sufrimiento humano, solo en ciertos casos tales como los bebés, dada la complejidad de nuestras estructuras afectivas y cognitivas, estructuras que compartimos en alto grado con los grandes simios $y$, en menor grado, con otros animales meramente sintientes. La evolución de nuestra moralidad parece avocarnos a darles un mejor trato a los animales.

Aun cuando muchos animales sociales han desarrollado tendencias afectivas y altruistas, es raro que dirijan dichas tendencias a otras especies...Somos la primera especie en aplicar estas tendencias que evolucionaron dentro del grupo a un círculo más amplio de humanos y podemos hacer lo mismo con otros animales: el trato humanitario y no los derechos se convertirán entonces en la pieza central de nuestra actitud hacia los mismos (De Waal, 2007, pp. 107-108).

Si ser liberal significa poder ampliar el círculo de consideración moral para incluir seres tradicionalmente excluidos de dicha esfera, entonces el darwinismo nos permitirá ser personas más solidarias con los animales porque nos sentiremos más humanos si no los maltratamos. Una manera de expandir tal círculo podría inspirarse en la noción de justicia como lealtad ampliada: darle la misma protección a esos miles de seres anónimos que la que se le da a una mascota. 
Regreso de nuevo a la lectura de Muerte en la tarde. Hemingway clasifica a los seres humanos en dos grupos: los que tienen la capacidad de identificarse con los animales porque son capaces, de ponerse en su lugar, y los que no se identifican con los animales, sino con los seres humanos. $Y$ al respecto hace una observación interesante:

Creo por mi experiencia y mis observaciones, que los que se identifican con los animales, los amigos profesionales de los perros y de otros animales, son capaces de mayor crueldad con los seres humanos que quienes no se identifican espontáneamente con los animales. Parece que hubiera como una separación fundamental entre las gentes con relación a esto. Pero los que no se identifican con los animales, pueden, sin querer a todos los animales, sentir afecto por un animal individual, un perro, un gato, un caballo, por ejemplo, aunque luego fundamenten este cariño en una cualidad del animal o en cualquier asociación de sentimientos que les sugiera, más que en el hecho de que sea un animal y de que merezca ser amado (Hemingway, 1985, pp.10-11).

Tal vez, Hemingway estaría de acuerdo en que los amigos profesionales "de los perros y de otros animales" paradigmáticamente fueron los nazis porque fueron capaces de una crueldad infinita con los seres humanos en comparación con otras formas de crueldad históricas. Si se ama más a un perro que a otro ser humano, como Hitler hizo, entonces hubo una falta de lealtad con la humanidad y eso explicaría su crueldad. Pero ies posible reinterpretar este texto y considerar que algunos fanáticos de la causa animalista, exacerbados por una versión simplista y dogmática de ella, podrán ser más leales a los animales que a la propia especie humana? Creo que tal peligro existe y es inminente ante la actual crisis ecológica.

De hecho, hay formas de ecología profunda que rayan, como toda buena ideología dogmática, con formas de fanatismo semejantes a las de la ideología nazi: el llamado ecofascismo. Hay quienes han propuesto una suerte de "solución final" al mejor estilo nazi, para que la problemática ecológica se resuelva a favor del mundo natural y no del hombre, afirmando que la naturaleza volverá a recobrar su "equilibrio" y su vitalidad sólo si se elimina la cumbre de la cadena alimenticia, esto es, el hombre. Incluso ha habido otros fanáticos que han Ilegado a afirmar que la humanidad es una especie de virus que se ha diseminado por la biosfera y que debe ser perseguido y eliminado con el antivirus del VIH (Herman, 1998). El igualitarismo animal tiene el enorme reto de no caer en las tentaciones del ecofacismo, pues para muchos animalistas radicales la liberación animal no es posible sin recurrir a algún tipo violencia, por lo menos, en contra de la propiedad. Si dicha violencia está moralmente justificada, ¿̇lo estará alguna vez la violencia en contra de las personas? Afortunadamente, tanto Singer como Regan condenan el uso de medios violentos de cualquier tipo en la lucha por los derechos de los animales. La cuestión es si los activistas respetarán tal condena. Saber en qué medida debemos combinar el arduo trabajo conceptual con la 
educación de nuestros sentimientos morales, determinará que los animalistas tanto como sus opositores, eviten caer en posiciones acríticas que alimenten un amargo dogmatismo de lado y lado que no nos permita avanzar en la urgente e inaplazable construcción de una ética animal crítica

\section{Referencias}

Aaltola, E. (2013). Skepticism, Empathy, and Animal Suffering. Bioethical Inquiry, 10, 457-446.

Aaltola, E. (2012). Animal suffering: Philosophy and culture. New York: Palgrave.

Andrews, K. (2011). Beyond Anthropomorphism: Attributing Psychological Properties to Animals. En T. L. Beauchamp; R. G. Frey (Eds.). The Oxford Handbook of Animals Ethics (69-94). Oxford: Oxford University Press.

Arluke, A. and Sax, B. (1992). Understanding Nazi animal protection and the holocaust. Anthrozoös, 5, 6-31.

Coetzee J. M. (2004). Elizabeth Costello. México: Debolsillo.

De Cruz, H. and De Smed, J. (2012). Evolved cognitive Biases and the Epistemic Status of Scientific Beliefs. Philosophical Studies, 147 (4), 411-429.

De Wall, F.(2009). Primates y filósofos. La evolución de la moral del simio al hombre. Paidós: Barcelona.

Dennett, D. (2007). Romper el hechizo. La religión como fenómeno natural. Buenos Aires: Katz.

Hemingway, E. (1985). Muerte en la tarde. Bogotá: Seix-Barral.

Ferry, L. (1993). El nuevo orden ecológico. Barcelona: Tusquets

Gruen, L. (2009). Attending to nature: empathetic engagement with the more than human world. Ethics \& the Environment, (14), 23-38.

Guthrie, S. (1993). Faces in the Clouds. A New Theory of Religion. New York: Oxford University Press.

Henry, B. (2006). Empathy, home environment, and attitudes toward animals in relation to animal abuse. Anthrozoös 19, 17-34. 
Herman, A. (1998). La idea de decadencia en la historia occidental. Barcelona: Andrés Bello.

Horn, J. (2016). Moral Realism, Fundamental Moral Disagreement, and Moral Reliability. The Journal of Value Inquiry. Doi: 10.1007/s10790-016-9583-4.

Kahane, G. (2011). Evolutionary Debunking Arguments. Nous, 45, 103-125.

Kasperbauer, T. (2014). Rejecting Empathy for Animal Ethics. Ethical Theory and Moral Practice, 18, 817-833.

Machuca, D. (2013). Disagreement and Skepticism. London: Routledge.

Nussbaum, M. (2008). Fronteras de la justicia. Barcelona: Paidós.

Ogien, R. (2009). La influencia del olor de lo cruasanes calientes sobre la bondad humana. Madrid: Aguilar.

Oxley, J. (2011). The moral dimensions of empathy. Palgrave Macmilan: New York.

Patterson, Ch. (2009). ¿Por qué maltratamos tanto a los animales? Un modelo para la masacre de personas en los campos de exterminio nazis. Lleida: Editorial Milenio.

Pérez, M. (2011). Un primate de tercera y una persona de segunda. Universitas Philosophica, 57(28), 265-293.

Prinz, J. (2011). Is empathy necessary for morality? En Coplan, A. y Goldie, P. (Ed.). Empathy: Philosophical and psychological perspectives (519-38). Oxford: University Press.

Regan, T. (1983). The case of animal rights. Berkeley: University of California Press.

Scotto, C. (2015). Empatía, antropomorfismo y cognición animal. Principia, 19(3), 423-452.

Singer, P. (1993). Ética práctica. Cambridge: Cambridge University Press.

Street, S. (2006). A Darwinian Dilemma for Realist Theories of Value. Philosophical Studies, 127(1), 109-166.

Sztybel, D. (2006). Can the treatment of animals be compared to the Holocaust? Ethics \& the Environment, 11(1), 97-132. 